\title{
К ВОПРОСУ О СОЗДАНИИ ТРЕХМЕРНОГО КАДАСТРА НА ЗАСТРОЕННЫХ ТЕРРИТОРИЯХ
}

\section{Евгений Ильич Аврунев}

Сибирский государственный университет геосистем и технологий, 630108, Россия, г. Новосибирск, ул. Плахотного, 10, кандидат технических наук, директор Института кадастра и приподопользования, тел. (913)901-32-66, e-mail: kadastr204@yandex.ru

\section{Валерия Владимировна Вылегжанина}

Сибирский государственный университет геосистем и технологий, 630108, Россия, г. Новосибирск, ул. Плахотного, 10, кандидат технических наук, доцент кафедры кадастра и территориального планирования, тел. (961)845-44-09, e-mail: Valeria741974@mail.ru; Управление Федеральной службы государственной регистрации, кадастра и картографии по Новосибирской области, 630091, г. Новосибирск, ул. Державина, 28, главный специалист-эксперт отдела правового обеспечения, тел. (383)227-10-76, e-mail: pravo@uy.nsk.su

\section{Ильгиз Ахатович Гиниятов}

Сибирский государственный университет геосистем и технологий, 630108, Россия, г. Новосибирск, ул. Плахотного, 10, кандидат технических наук, доцент кафедры кадастра и территориального планирования, тел. (383)344-31-73, e-mail: kadastr204@yandex.ru

В статье рассматривается проблема отсутствия актуальных сведений о подземных коммуникациях, расположенных в границах муниципальных образований. Данный аспект негативно отражается на эффективности использования земельных ресурсов органами государственной власти и органами местного самоуправления в рамках управления развитием территорий, а также при проектировании и строительстве объектов градостроительной деятельности. Разрозненность информации, содержащейся в Едином государственном реестре недвижимости (ФГИС ЕГРН) и Федеральной государственной информационной системе территориального планирования (ФГИС ТП) затрудняет разработку и использование проекта планировки территории в целях устойчивого развития территорий.

Для решения обозначенной проблемы предлагается включение в состав комплексных кадастровых работ технологической операции по установлению местоположения подземных коммуникаций и внесение соответствующих сведений о них в ЕГРН. Кроме этого, учитывая актуальность интеграции градостроительной и кадастровой деятельности, предлагается объединить информацию, содержащуюся в ФГИС ЕГРН и ФГИС ТП, на базе единой цифровой информационной платформы в 3D формате.

Ключевые слова: подземные коммуникации, управление развитием территорий, комплексные кадастровые работы, сведения, Единый государственный реестр недвижимости, Федеральная государственная информационная система территориального планирования, стадия разрытия грунта, единая информационная платформа, 3D формат

\section{CREATION OF THREE-DIMENSIONAL CADASTRE IN BUILT-UP AREAS}

\section{Evgeny I. Avrunev}

Siberian State University of Geosystems and Technologies, 10, Plakhotnogo St., Novosibirsk, 630108, Russia, Ph. D., Director, Institute of Cadastre and Environmental Management, phone: (383)344-31-73, e-mail: kadastr204@yandex.ru 


\section{Valerija V. Vylegzhanina}

Siberian State University of Geosystems and Technologies, 10, Plakhotnogo St., Novosibirsk, 630108, Ph. D., Associate Professor, Department of Cadastre and Territorial Planning, phone: (383)344-31-73, e-mail: Valeria741974@mail.ru; Federal Service of State Registration, Cadastre and Cartography for Novosibirsk region, 28, Derzhavina St., Novosibirsk, 630091, Russia, Chief Expert of Law Department, phone: (383)227-10-76, e-mail: pravo@uy.nsk.su

\section{Ilgiz A. Giniyatov}

Siberian State University of Geosystems and Technologies, 10, Plakhotnogo St., Novosibirsk, 630108, Russia, Ph. D., Associate Professor, Department of Cadastre and Territorial Planning, phone: (383)344-31-73, e-mail: kadastr204@yandex.ru

The article considers the problem of lack of up-to-date information about underground communications located within the boundaries of municipalities. This aspect negatively affects the efficiency of the use of land resources by state authorities and local authorities in the framework of territorial development management, as well as in the design and construction of urban planning facilities. The fragmentation of information contained in the Unified State Register of Real Estate (FGIS USRN) and the Federal State Information System for Territorial Planning (FGIS TP) makes it difficult to develop and use a planning project for the sustainable development of territories. To solve this problem, it is proposed to include in the complex cadastral work a technological operation for establishing the location of underground facilities and entering relevant information about them in the USRN. In addition, taking into account the relevance of the integration of urban planning and cadastral activities, it is proposed to combine the information contained in the USRN and TP FGIS on the basis of a single digital information platform in 3D format.

Keywords: underground facilities, territory development management, complex cadastral works, information, Unified State Register of Real Estate, Federal State Information System of Territorial Planning, stage of soil development, unified information platform, 3D format

Современная действительность вносит свои коррективы в жизнь общества, в построение прямой и обратной связи между населением, находящимся в пределах муниципальных округов и иных территорий, и управленческими структурами $[1,2]$. Информация в цифровом виде, актуальность, удобство и эффективность использования цифровых платформ органами государственной власти и органами местного самоуправления в рамках управления развитием территорий - аспекты, без которых невозможно развитие земельно-имущественных отношений [3].

Растущие потребности общества и бизнеса приводят к расширению границ муниципальных образований и увеличению плотности застройки территорий городов и сельских поселений. Указанные обстоятельства требуют основательного и детального подхода к подготовке проектов документов территориального планирования и материалов по их обоснованию $[4,5]$.

Дополнительную сложность процессу добавляет наличие подземных инженерных коммуникаций, созданных до введения в действие учетнорегистрационной системы, поскольку сведения об указанных объектах недвижимости, как правило, в ЕГРН отсутствуют. Базы коммунальных служб также устарели, а имеющаяся информация частично утратила свою актуальность [6]. 
Отсутствие достоверной информации о подземных объектах в проекте планировочной структуры может обернуться неблагоприятными последствиями как для собственника или пользователя земельного участка, застройщика, так и для собственника самого объекта недвижимости, в частности, линейного.

Опытные застройщики не доверяют имеющейся официальной информации, предоставленной коммунальными службами, и проводят дополнительные инженерно-геодезические изыскания, на предмет выявления неопознанных подземных инженерных линейно-сетевых объектов, что предполагает дополнительные существенные денежные затраты.

Необходимо отметить, что действующим законодательством предусмотрено проведение комплексных кадастровых работ, в рамках которых осуществляется:

- уточнение местоположения границ земельных участков и расположенных на них зданий, сооружений, объектов незавершенного строительства;

- исправление реестровых ошибок в сведениях о местоположении границ объектов недвижимости;

- образование новых земельных участков [7].

Таким образом, в рамках комплексных кадастровых работ необходимо проводить инженерно-геодезические обследования территорий для выявления подземных линейных объектов и актуализации сведений о точном их месте расположения в виде координат точек начала и конца сооружений, вершин их углов поворота, в том числе и глубине залегания [8]. Пример подобных работ приведен на рисунке [9].

Информация об обнаруженных подземных сооружениях должна быть внесена в ЕГРН, с последующим установлением собственника указанного объекта [10].

Вместе с тем, необходимо учитывать требования действующего законодательства о наличии в ЕГРН информации об охранных зонах, установленных для линейных объектов. Данный аспект, позволит проанализировать возможность использования исследуемого земельного участка в соответствии с видом разрешенного использования, установленного градостроительным регламентом, действующим на территории конкретного муниципального образования [11] и позволит инвесторам точнее ориентироваться в бизнес проектах.

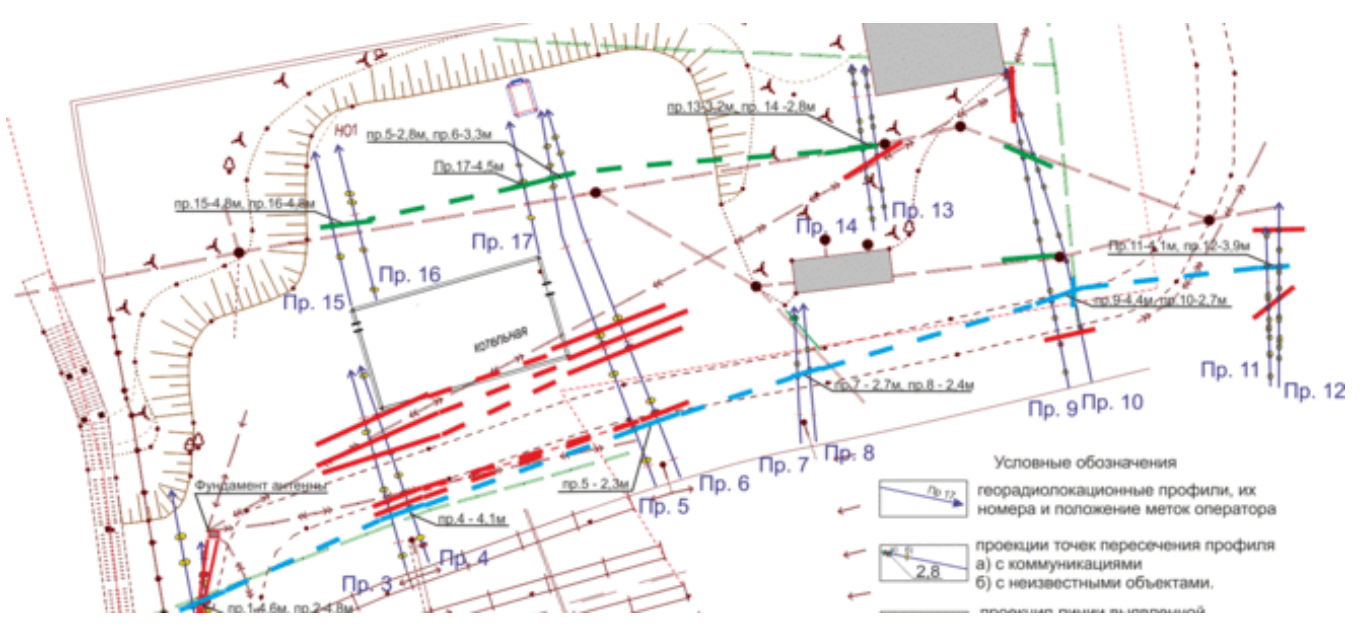

Пример работ по выявлению подземных коммуникаций в рамках геодезических исследований, проведенных ООО «Пермгеорадар», г. Пермь 
Исходя из целей, обозначенных Градостроительным кодексом Российской Федерации [12], ФГИС ТП содержит информацию, необходимую для подготовки документов территориального планирования, в том числе:

- проектов документов территориального планирования и материалов по обоснованию таких проектов;

- документов территориального планирования;

- правил землепользования и застройки;

- цифровых топографических карт, не содержащих сведений, отнесенных к государственной тайне.

Вместе с тем, ФГИС ТП содержит информацию, которая дублирует сведения, содержащиеся в ФГИС ЕГРН, а именно:

- границы субъектов Российской Федерации, муниципальных образований, населенных пунктов;

- размещение объектов федерального, регионального, местного значения;

- зоны с особыми условиями использования территорий;

- территории объектов культурного наследия;

- особо охраняемые природные территории;

- особые экономические зоны;

- иная информация о состоянии, использовании, ограничениях использования территорий [12].

Таким образом, было бы уместно говорить о создании единой цифровой платформы, основанной на базе слияния данных ФГИС ЕГРН и ФГИС ТП. Причем основной целью, объединяющей перечисленные цифровые платформы, является оказание государственных и муниципальных услуг по предоставлению достоверной информации пользователям - с одной стороны и совершенствование деятельности органов государственной власти и органов местного самоуправления в рамках управления развитием территорий с другой стороны.

Указанные преобразования вызваны развитием цифровых технологий во всех отраслях жизни и деятельности современного общества. Примером тому является создание генерального плана города Новосибирска на цифровой основе, содержащего порядка 45 информационных графических слоев. В основу генерального плана города заложена, в частности, Стратегия социальноэкономического развития муниципального образования Новосибирск [13].

Указанный проектный документ предполагает комплексное освоение городских территорий, на которых расположен ветхий и аварийный жилой фонд, неэффективно используемые территории промышленных объектов, а также зоны поэтапной реновации застроенных территорий [14].

Это значит, что подземная инженерная инфраструктура города требует пристального внимания, поскольку возведение новых объектов капитального строительства на освобожденных территориях, невозможно без актуальной ин- 
формации о существующих подземных сооружениях. Таким образом, ведение государственного кадастра в 3D формате - необходимость, вызванная современностью.

Обобщая вышесказанное, необходимо отметить, что 3D-кадастр успешно применяется в странах Евросоюза. Возможности 3D-кадастра позволяют обеспечить:

- многоцелевое использование поверхностных участков земли;

- многоцелевое использование надземных участков;

- многоцелевое использование подземных участков [15].

Повсеместная цифровизация уверенно завоевывает все пространство современного градостроительного проектирования. Поэтому данный факт уже не требует необходимости каких-либо дополнительных обоснований.

Вместе с тем, единая цифровая информационная платформа, содержащая актуальные сведения о территориях и расположенных на них объектах в цифровом 3D формате, позволит значительно ускорить процесс принятия решений по развитию территорий, как с точки зрения концептуальных подходов социальной направленности, так и фундаментального многоотраслевого территориального развития региона, района, города.

\section{БИБЛИОГРАФИЧЕСКИЙ СПИСОК}

1. Карпик, А. П. Электронное геопространство - сущность и концептуальные основы [Текст] / А. П. Карпик, Д. В. Лисицкий // Геодезия и картография. -2009. - № 5. - С. 41-44.

2. Карпик А. П. Применение сведений государственного кадастра недвижимости для решения задач территориального планирования // Известия вузов. Геодезия и аэрофотосъемка. - 2013. - № 6. - С. 112-117.

3. Лисицкий, Д. В. Технологическая платформа «Единое геоинформационное пространство» - основа социально-экономического развития территорий [Текст] / Д. В. Лисицкий, С. Ю. Кацко // Известия вузов. Геодезия и аэрофотосъемка. - 2015. -№ 5/С. C. 250-256.

4. Карпик, А. П. Сущность геоинформационного пространства территорий как единой основы развития государственного кадастра недвижимости [Текст] / А. П. Карпик, В. С. Хорошилов // Изв. вузов. Геодезия и аэрофотосъемка. - 2012. - № 1. - С. 134-136.

5. Карпик А. П. Системная связь устойчивого развития территорий с его геодезическим информационным обеспечением // Вестник СГГА. - 2010. - Вып. 1 (12). - С. 3-11.

6. Аврунев, Е. И. Проблемы кадастровой деятельности [Текст] / Е. И. Аврунев, А. И. Каленицкий, В. Н. Клюшниченко // Известия вузов. Геодезия и аэрофотосъемка. 2015. - № 5/C.- С. 99-103.

7. Письмо Федеральной службы государственной регистрации, кадастра и картографии от 01.10 .2020 № 13-8646-АБ/20[Электронный ресурс]. - Режим доступа: http://www.consultant.ru.

8. Аврунев, Е. И. Геодезическое обеспечение государственного кадастра недвижимости [Текст] / Е. И. Аврунев. - Новосибирск : СГГА, 2010.

9. Официальный сайт ООО "Пермгеорадар". URL: http://permgeoradar.ru/contacts (дата обращения: 28.10.2020).

10. Федеральный закон "О государственной регистрации недвижимости" от 13.07.2015 N 218-Ф3 [Электронный ресурс]. - Режим доступа: http://www.consultant.ru. 
11. Аврунев Е.И., Вылегжанина В.В., Гиниятов И.А. Некоторые аспекты учета и регистрации прав на линейные объекты Интерэкспо ГЕО-Сиби-рь. XVI Междунар.науч. конгр., 18 июня -8 июля 2020 г., Новосибирск [Текст]: сб. мате-риалов в 8 т. Т. 3:Национальная науч. конф. «Экономическое развитие Сибири и Дальнего Востока. Экономика природопользования, землеустройство, лесоустройство, управление недвижимостью».- Новосибирск: СГУГиТ, 2020. № 2. - С. 12-18. DOI: 10.33764/2618-981X-2020-3-2-12-18.

12. "Градостроительный кодекс Российской Федерации" от 29.12.2004 N 190-Ф3 (ред. от 31.07.2020) (с изм. и доп., вступ. в силу с 28.08.2020) [Электронный ресурс]. - Режим доступа: http://www.consultant.ru.

13. Виктор Тимонов: "Это будет совершенно новый Новосибирск" [Электронный ресурс]. - Режим доступа: http://vseon.com/analitika/mnenie-eksperta/viktor-timonov-eto-budetsovershenno-novyj-novosibirsk.

14. Официальный сайт города Новосибирска. URL: https://novosibirsk.ru/news/238822/(дата обращения: 28.10.2020).

15. Малыгина О.И. Трехмерный кадастр - основа развития современного мегаполиса. URL: http://www.elibrary.ru (дата обращения: 04.05.2015).

(C) Е. И. Аврунев, В. В. Вылегжанина, И. А. Гиниятов, 2021 